\title{
Methodology Approach to Choosing a Cloud Platform
}

\section{Sayenko Vladimir ${ }^{1}$}

Pavlenko Marko²
${ }^{1}$ Kharkiv National University of Radio Electronics, 14 Nauky Ave, KharkivUA-61166, Ukraine, vladimir.sayenko@nure.ua, l

${ }^{2}$ Kharkiv National University of Radio Electronics, 14 Nauky Ave, KharkivUA-61166, Ukraine,' marko.pavlenko@nure.ua

\begin{abstract}
Modern information systems today necessarily use cloud resources. But there is still the problem of choosing the best platform for remote access to computing resources. The following is a methodology approach to choosing a Cloud platform and provides recommendations for how to choose one of them. The methodology is based on the use of a specific system of criteria, the values of the estimates of these criteria and estimates of weighting factors of significance.
\end{abstract}

Keywords: Cloud Platforms, computing resources, criteria, estimation, AWS, Google Cloud platform, Microsoft Azure.

\section{Introduction and Problem statement}

Nowadays, the modern information systems necessarily use the cloud resources.

This concept provides for remote processing and storage of data. It gives Internet users access to the server's computer resources and to the software services as an online service. That is, if you have an Internet connection to the Cloud, you can perform complex calculations, process data using the power of a remote server. And you don't have to buy the right hardware. It is sufficient only to get the Internet connection.

The demand for such resources is huge. More and more offers appear on the market. Choosing a particular cloud service provider is an urgent task. This task is especially important for new pilot projects and start-ups.

Nowadays, there are many available efficient services in the cloud services market. A big world leader companies and small firms use these services today. Cloud platforms are not the same and differ in conceptual approach, set of provided services, prices, etc.. But, owners of Cloud services perform roughly the same actions - providing these services for free or for a fee. These services cover access to powerful computing resources, software, related technical documentation, and recommendations how to use all of the services.

Thus, we can distinguish the problem of choosing the best cloud platform for our needs. The choice is complicated because there are a lot of Cloud services in today's IT market. They have different characteristics and prices of services. But they are open for investigation and discovering to get the best solution and to find the best choice of the usage [1].

\section{PROBLEM SOLUTION AND RESULTS}

In order to choose the best cloud platform, all the financial, functional and technical requirements for the project should be defined and prioritize all needs.

The leaders of the modern European and American markets, which fully meet all the requirements of the basic criteria, can be called platforms from Amazon (AWS), Google Cloud and Microsoft Azure [2, 3, 4]. It should be noted that in the Asian market, the main leader is Alibaba Cloud (included in the holding of Alibaba Group).

It is proposed to perform the following three steps to choose a cloud platform: 1) Identify technologies; 2) Price and pricing model; 3) Evaluation of platforms by special criteria.

\section{A. Description of the methodology.}

The methodology involves a two-stage assessment. The first stage is a preliminary assessment. The second stage is a detailed assessment.

The first stage includes four steps: 1) Definition of technologies, 2) Cost models; 3) Compatibility with general requirements 4) Compatibility of the project with available specialists. At this stage we determine a quality estimation.

The second stage includes a detailed assessment of 6 criteria. At this stage we determine a quantity estimation. For each of criterion we use a significance coefficient and special expert evaluation.

\section{B. Description of the first stage}

1) Identify technologies. We need to determine what technologies, protocols, programming languages are required to complete your project. Do not consider platforms that do not provide these capabilities. Although today almost all platforms support services for all software platforms. There are only some differences in stability and reliability.

2) Cost models. In most cases, customers choose the financial and resource model of payment - it reflects the financial impact of resources on the service, which is more in line with the economic nature of cloud services. It takes into account not only the maximum number of virtual resources of the cloud platform (systems, clusters), but also other expensive equipment, that requires to be.

In general, the pricing model is the exchange process where the client/end-user pays for the services offered by the cloud provider.

Table 1. Cost models

\begin{tabular}{|l|l|}
\hline Provider & \multicolumn{1}{|c|}{ Cost model } \\
\hline AWS & $\begin{array}{l}\text { Fee per hour / week for resource use. } \\
\text { Fee for temporary / permanent data transfer, GB. }\end{array}$ \\
\hline $\begin{array}{l}\text { Google } \\
\text { Cloud }\end{array}$ & $\begin{array}{l}\text { Fee for basic kit by developer or professional (data } \\
\text { transfer, resources, consultation of technicians, etc.) }\end{array}$ \\
\hline $\begin{array}{l}\text { Microsoft } \\
\text { Azure }\end{array}$ & $\begin{array}{l}\text { Fee per hour / week for computing capacity and for } \\
\text { temporary / permanent storage of GB of data in storage }\end{array}$ \\
\hline
\end{tabular}

Cloud service providers have 2 main pricing models: static and dynamic. In the first case, the price remains unchanged after its determination, in the second case it changes 
dynamically according to the availability of resources, demand and so on.

Among the main fixed or variable factors that affect pricing in cloud providers are the following:

- Quality and cost of service;

- Investment amount (provider costs for cloud services)

- Lease contract term;

- Reputation of cloud users and providers.

3) Compatibility with general requirements. When developing systems, there are often requirements for compatibility of the developed system with existing ones and compatibility with customer requirements. A typical example for many solutions, it may be the best option - choose AWS, but there is the same requirement to choose only MS Azure.

\section{4) Compatibility of the project with available specialists.}

An important aspect when choosing a cloud platform is the availability of certified specialists for a particular platform. The more certificates and the higher the rank of certificates could help to choose the more compatibility cloud platform.

\section{Description of the second phase}

\section{5) Evaluation of platforms by special criteria}

a) Physical protection. This requirement is mandatory for any cloud platform, as the threat of cyberattacks is constantly increasing. For the protection, new and updated security tools are being added: unique scanning anti-virus programs and password encryption mechanisms in the database, bit-based data encryption in both parties, activation of server and client authentication and more

b) Legal protection. It will also be necessary to ensure not only that there is sufficient information but also legal and legislative protection of their data by the chosen platform. To do this, you need to carefully study and analyze the information regarding the Territorial Data Centers (TDC) in your country and the cloud platform you have chosen. It is recommended that all actions are complied with the European Package of Standards for Personal Data Protection

c) No hidden costs. As of 2019, about $75 \%$ of large corporations, small and medium-sized businesses, are experiencing financial problems: the difficulty of backing up, leasing space for equipment, inefficient use of resources, unauthorized use by employees of cloud-based competitors. Because of this, the overhead of platform maintenance is rising and companies are having to implement various hidden taxes.

d) Backuping and recovering of information. You need to know how often data is backed up, or if there is any mechanism in place. Each platform provides its own information recovery solution. Although each of them has many small details and features, there are fundamentally two approaches. This is done through stand-alone (database servers) or cloud-based virtual repositories.

e) Supporting. If you are planning on long-term use, you must ensure that the platform provides high-quality advice from highly qualified specialists. That you can get such help on a wide variety of technical issues, schematics and models for any possible transfer of projects to other platforms. Also you get clearly described documentation for setting your software up for any operating system..

f) Possibility of integration. The best way to get started with cloud technology and optimize existing resources is to use a hybrid cloud environment. Hybrid integration solutions provide
API support and enterprise connectivity, allowing applications, data and processes to be integrated quickly and easily. The best of hybridity is implemented in Microsoft Azure [6]

\section{PROBLEM SOLUTION AND RESULTS}

The following is a table of the cloud platform assessments of the offered criteria, and the coefficient of significance of each of the criteria in a specific example.

Table 2. Example

\begin{tabular}{|l|l|l|l|}
\hline \multicolumn{1}{|c|}{ Factors } & AWS & Google Cloud & Azure \\
\hline $\begin{array}{l}\text { No hidden costs } \\
\text { Significance coefficient } 0.8\end{array}$ & 7 & 8 & 8 \\
\hline $\begin{array}{l}\text { Physical protection } \\
\text { Significance coefficient } 0.9\end{array}$ & 8 & 9 & 9 \\
\hline $\begin{array}{l}\text { Legal protection } \\
\text { Significance coefficient } 0.8\end{array}$ & 9 & 9 & 9 \\
\hline $\begin{array}{l}\text { Backuping and recovering of } \\
\text { information Significance coefficient } 0.7\end{array}$ & 7 & 9 & 8 \\
\hline $\begin{array}{l}\text { Supporting } \\
\text { Significance coefficient } 0.6\end{array}$ & 8 & 8 & 6 \\
\hline $\begin{array}{l}\text { Possibility of integration } \\
\text { Significance coefficient } 0.5\end{array}$ & 8 & 7 & 9 \\
\hline
\end{tabular}

All estimates (weights) and significance factors are expert and for each individual case they will be individual. Table 2 shows an example of criteria evaluation and decision making. Let we have a result of expert evaluation for all 6 factors. For each factor, its own significance coefficient was chosen. For each cloud platform was determined the weight.

The sum of the values of the criterion scores, which are multiplied by the significance factor, we obtain the following average scores: AWS - 32.9 points, Google Cloud - 36.3 points, Azure - 35.4 points. Google Cloud Service Providers dominate the average Azure margin and AWS by a significant margin. However, if any of the evaluation criteria is not essential to a particular project, its coefficient may be reduced, the estimates re-listed and another platform selected.

\section{CONCLUSIONS}

A methodology for evaluating the feasibility of using a cloud platform is proposed. It could be used in the implementation of a project for the development of information systems. The methodology is based on the use of a specific system of criteria, the values of the estimates of these criteria and estimates of weighting factors of significance. The proposed methodology does not provide accurate estimates and can serve as a starting point for the final decision on the choice of a cloud platform.

\section{REFERENCES}

[1] Bogdanov, A.V. The comparison of several cloud computing platforms /A.V. Bogdanov, E. Mint. Ning; UDK 519.687.7. - Rel.№2, ser. №10. St. Petersburg: Herald SPbSU, 2013. — 9c.

[2] Amazon Web Services: AWS Documentation. URL: https://docs.aws.amazon.com/.

[3] Google Cloud Platform: GCP Documentation. URL https://cloud.google.com/docs/

[4] Microsoft Azure: Azure Documentation. URL: https://docs.microsoft.com/en-us/azure/.

[5] The cloud battle: Google vs. Microsoft vs. Amazon. URL: https://enonic.com/blog/cloud-battle-google-microsoft-amazon 